\title{
Differentiation of Pituitary Adenomas From Other Sellar and Parasellar Tumors by ${ }^{99 m}$ Tc(V)-DMSA Scintigraphy
}

\author{
Koji YAMAMURA, Shinichi SUZUKI*, and Isao YAMAMOTO* \\ Department of Neurosurgery, Yokohama City University Medical Center, Yokohama, Kanagawa; \\ *Department of Neurosurgery, Yokohama City University, Yokohama, Kanagawa
}

\begin{abstract}
Pentavalent technetium-99m dimercaptosuccinic acid [99m Tc(V)-DMSA] scintigraphy was evaluated for the differentiation of pituitary adenomas, especially non-functioning adenomas, from other sellar and parasellar lesions. Diffuse ${ }^{99 \mathrm{~m}} \mathrm{Tc}(\mathrm{V})$-DMSA accumulation within the tumor was found in seven of seven non-functioning, three of four growth hormone-secreting, and seven of eight prolactin-secreting adenomas, but only partial accumulation in only two of 16 non-pituitary adenomas and normal pituitary glands. There were no significant relationship between tumor-to-background ratios and tumor size or serum hormone level. ${ }^{99 \mathrm{~m}} \mathrm{Tc}(\mathrm{V})$-DMSA scintigraphy showed overall sensitivity of $81 \%$ (17/21 cases) for detecting pituitary adenomas, in particular $100 \%$ for non-functioning adenomas. ${ }^{99 m}$ Tc(V)-DMSA may be useful for detecting pituitary adenomas, especially non-functioning adenomas, and for the differentiation of non-functioning pituitary adenomas from other sellar and parasellar lesions.
\end{abstract}

Key words: pentavalent technetium-99m dimercaptosuccinic acid, scintigraphy, pituitary adenoma

\section{Introduction}

Definite preoperative diagnosis of lesions in the sellar and parasellar regions is important to select the optimum surgical approach and for the clinical management of the patient. Computed tomography (CT) and magnetic resonance (MR) imaging provide various information and can delineate these lesions clearly, but differential diagnosis is sometimes difficult. ${ }^{2)}$ Pituitary adenomas are common tumors in the sellar region, and endocrine evaluation can establish the correct diagnosis of functioning pituitary adenomas, but provides few specific indicators for non-functioning pituitary adenomas.

Pituitary tumor with somatostatin receptors can be visualized with iodine-123- or indium-111-labeled octreotide. $^{8)}$ Most growth hormone (GH)- and thyroid-stimulating hormone-secreting and about $20 \%$ of non-functioning adenomas can be visualized clearly, but not other types of pituitary adenomas such as prolactin (PRL)- and adrenocorticotropic hormone (ACTH)-secreting and $80 \%$ of non-functioning adenomas without somatostatin receptors. ${ }^{8)}$

The present study assessed the use of pentavalent technetium-99m dimercaptosuccinic acid [ ${ }^{99 \mathrm{~m}} \mathrm{Tc}(\mathrm{V})-$ DMSA] scintigraphy for the differentiation of sellar and parasellar lesions.

\section{Clinical Materials and Methods}

The study included 37 patients with sellar and parasellar lesions, 27 females and 10 males aged 15-72 years. Thirty-two patients underwent surgery and the diagnosis was confirmed by histological studies. In the other five patients, the diagnosis was four normal pituitary glands and one case of radiation necrosis based on MR imaging and clinical evaluation. ${ }^{99 \mathrm{~m}} \mathrm{Tc}(\mathrm{V})$-DMSA scintigraphy was performed prior to the surgical procedure after obtaining informed consent. The 37 patients were divided into two groups: the pituitary adenoma group (PA group in Table 1) and the non-pituitary adenoma group (non-PA group in Table 2). Five patients with PRL-secreting adenomas in the PA group (Cases 8, 9, 11,12 , and 13) were receiving bromocriptine therapy at the time of ${ }^{99 \mathrm{~m}} \mathrm{Tc}(\mathrm{V})$-DMSA scintigraphy.

${ }_{99 \mathrm{~m}} \mathrm{Tc}(\mathrm{V})$-DMSA was prepared using a commercially available DMSA kit (Techne DMSA kit;

Received April 23, 2002; Accepted November 18, 2002

Author's present address: K. Yamamura, M.D., Department of Neurosurgery, Yokohama Minamikyosai Hospital, Yokohama, Kanagawa, Japan. 
Table 1 Summary of patients with pituitary adenoma

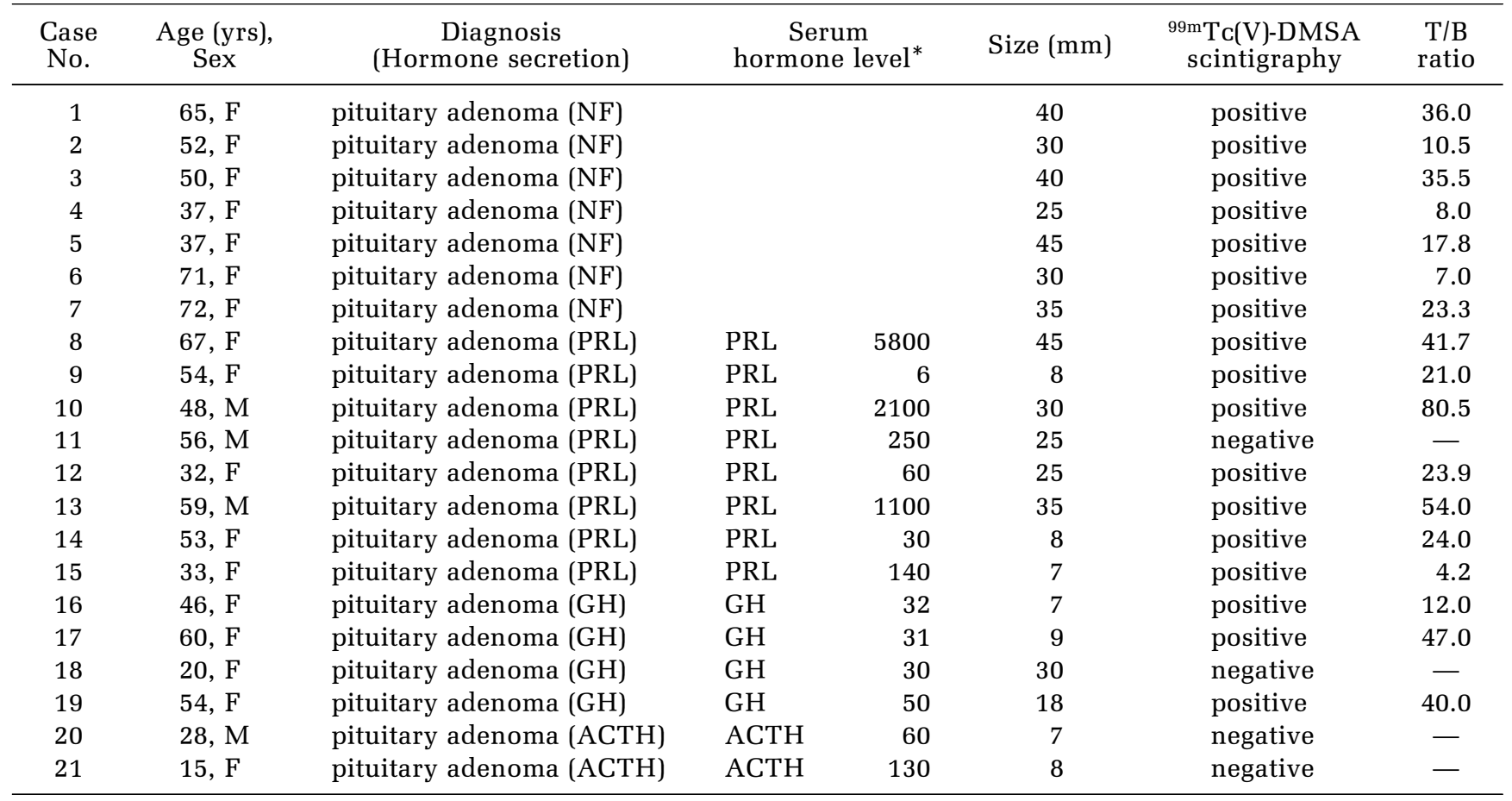

${ }^{*}$ Prolactin (PRL) and growth hormone (GH) levels in $\mathrm{ng} / \mathrm{ml}$, adrenocorticotropic hormone (ACTH) level in pg/ml. 99m Tc(V)-DMSA: pentavalent technetium-99m dimercaptosuccinic acid, NF: non-functioning, T/B: tumor/background.

Table 2 Summary of patients with non-pituitary adenoma

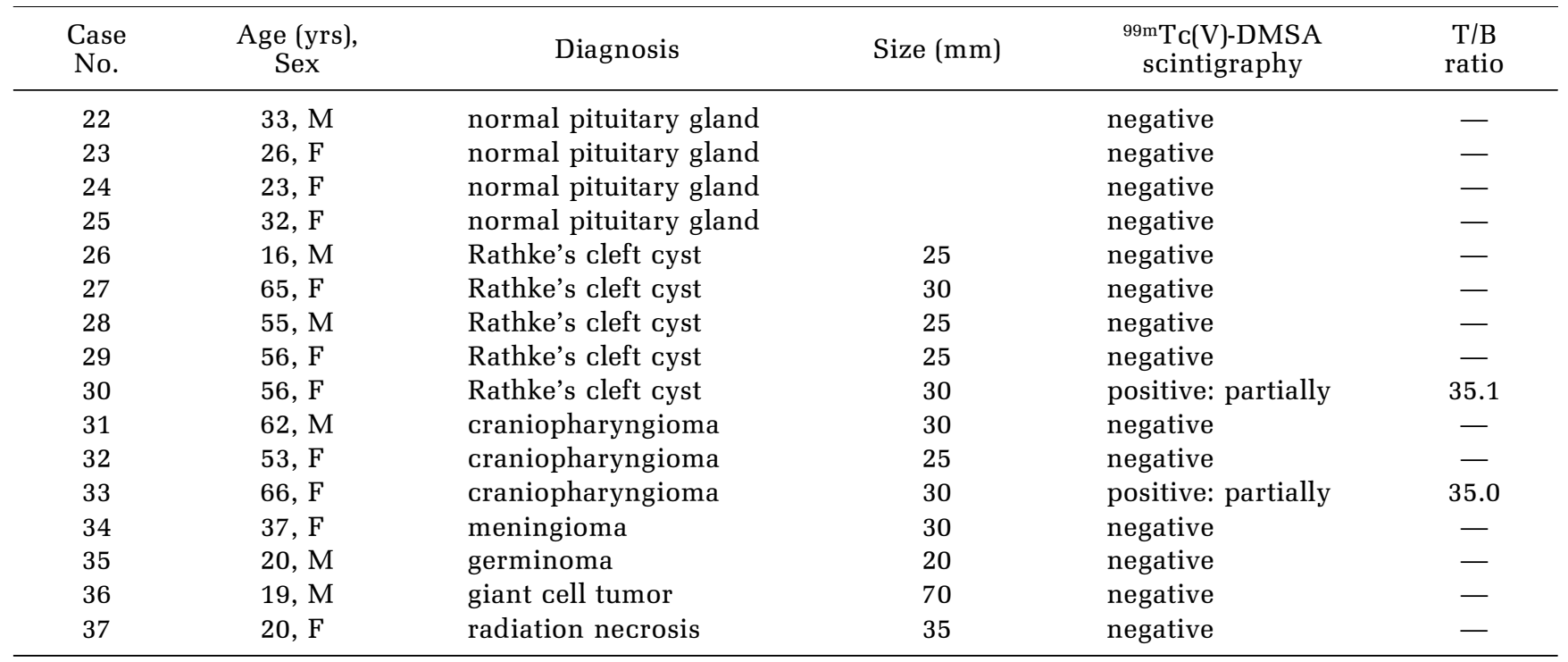

${ }^{99 m} \mathrm{Tc}(\mathrm{V})-D M S A:$ pentavalent technetium-99m dimercaptosuccinic acid, T/B: tumor/background.

Daiichi-radioisotope, Tokyo) by adding $250 \mu \mathrm{l}$ of $7 \%$ sodium bicarbonate solution $\left(\mathrm{NaHCO}_{3}\right)$ and reconstituting with $2 \mathrm{ml}$ of ${ }^{99 \mathrm{~m} T c}$ pertechnetate solution. ${ }^{4)}$
An intravenous bolus injection of ${ }^{99 \mathrm{~m}} \mathrm{Tc}(\mathrm{V})-\mathrm{DMSA}$ (740 MBq) was given to each patient. Lateral (left and right) planar images of the head were acquired 
using a gamma camera (Starcam 3000X C/T; GE Medical Systems, Milwaukee, Wis., U.S.A.) with a low-energy high-resolution collimator (photopeak $140 \mathrm{kV} \pm 10 \%$ ) for 3 minutes at 2 hours after injection. Patients with marked accumulation of ${ }^{99 \mathrm{~m}} \mathrm{Tc}(\mathrm{V})-$ DMSA in the lesion on the planar images were considered to show positive uptake. Single photon emission computed tomography (SPECT) studies were then acquired immediately for positive cases. The acquisition parameters were 64 projections over a $360^{\circ}$ rotation, 20 seconds per step, and a $64 \times 64$ matrix. The projection datasets were pre-filtered with a Butterworth filter (cut-off frequency $0.45 / \mathrm{cm}$, order 10), and reconstructed using a ramp filter (attenuation correction threshold 10\%, coefficient $0.11 / \mathrm{cm}$ ) and filtered back-projection. The regions of interest of both the tumor ( $\mathrm{T}$ ) and the paraventricular white matter (B) were drawn manually with the same areas to calculate the tumor-to-background ( $\mathrm{T} / \mathrm{B})$ ratio.

The chi-square test was used to compare the ${ }^{99 \mathrm{~m}} \mathrm{Tc}(\mathrm{V})$-DMSA accumulation rate between groups or subgroups. Student's t-test was used to compare the T/B ratio. Spearman's non-parametric test was used to assess correlations between the $\mathrm{T} / \mathrm{B}$ ratio and hormone levels, and size of lesion.

\section{Results}

Nineteen patients (17 in the PA group and 2 in the non-PA group) showed positive uptake on ${ }^{99 m} \mathrm{Tc}(\mathrm{V})-$ DMSA scintigraphy, with a significant gradient with the surrounding tissues. In the PA group, seven of seven non-functioning, three of four GH-secreting, and seven of eight PRL-secreting adenomas were positive. However, there was no ${ }^{99 \mathrm{~m}} \mathrm{Tc}(\mathrm{V})$-DMSA accumulation in ACTH-secreting adenoma (Table 1). All 17 positive pituitary adenomas accumulated ${ }^{99 \mathrm{~m}} \mathrm{Tc}(\mathrm{V})$-DMSA diffusely within the tumor (Figs. 1-3), whereas two positive non-pituitary adenomas, one craniopharyngioma and one Rathke's cleft cyst (Table 2), only partially accumulated ${ }^{99 \mathrm{~m}} \mathrm{Tc}(\mathrm{V})$-DMSA in the anterior part of the sella (Fig. 4).

${ }^{99 \mathrm{~m}} \mathrm{Tc}(\mathrm{V})-\mathrm{DMSA}$ accumulation showed significant differences between the PA group (17 of 21 patients) and the non-PA group ( 2 of 16 patients) ( $p<0.01$ ), especially between non-functioning adenomas and the non-PA group ( $p$ 0.01) (Fig. 5).

${ }^{99 m} \mathrm{Tc}(\mathrm{V})$-DMSA accumulation showed no statistical differences between macroadenoma (12 of 14) and microadenoma (5 of 7 ) in the PA group. The T/B ratio was highest in PRL-secreting adenomas (mean \pm SD $35.5 \pm 23.5$ ), followed by GH-secreting adenomas $(33.0 \pm 15.1)$ and non-functioning adenomas

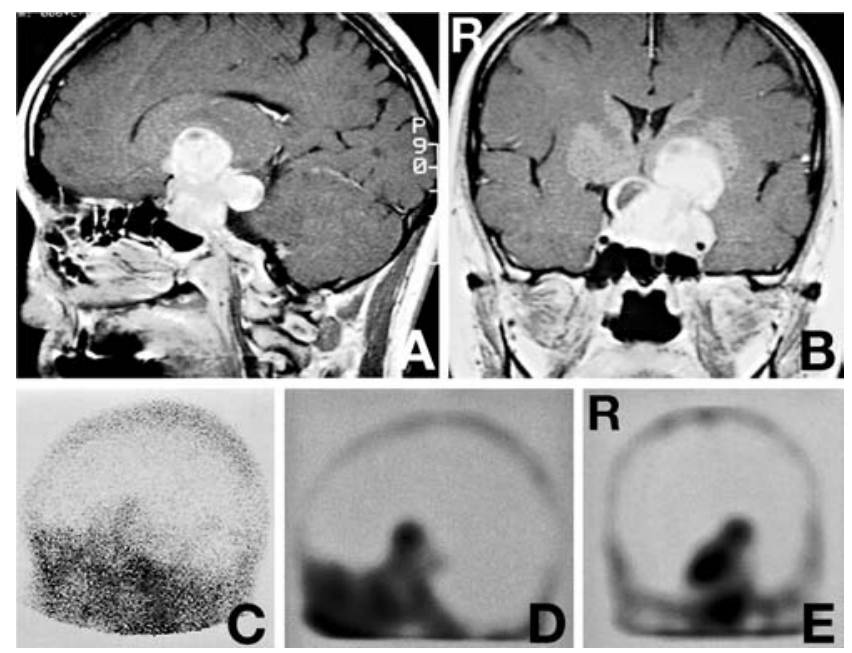

Fig. 1 Case 5. A 37-year-old female with nonfunctioning adenoma. Sagittal (A) and coronal (B) $\mathrm{T}_{1}$-weighted magnetic resonance images with gadolinium revealing a huge, irregular shaped, solid enhanced mass with a small cyst in the suprasellar region. Pentavalent technetium-99m dimercaptosuccinic acid [99mTc(V)-DMSA] scintigram (C) revealing marked diffuse accumulation of ${ }^{99 m}$ Tc(V)-DMSA within the lesion, and sagittal (D) and coronal (E) ${ }^{99 \mathrm{~m}} \mathrm{Tc}(\mathrm{V})$-DMSA single photon emission computed tomography scans revealing ${ }^{99 \mathrm{~m}} \mathrm{Tc}(\mathrm{V})$-DMSA accumulation more clearly (tumor-to-background ratio 17.8 ).
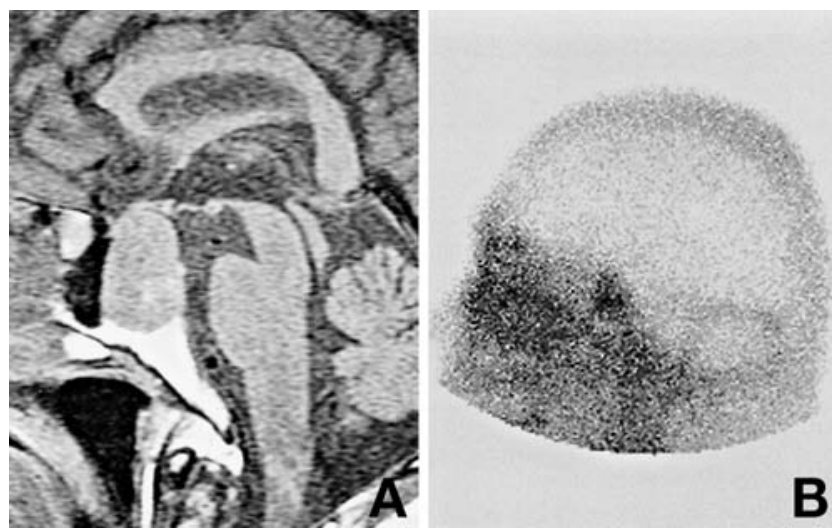

Fig. 2 Case 10. A 48-year-old male with prolactinsecreting adenoma. Sagittal $T_{1}$-weighted magnetic resonance image (A) revealing a solid mass in the dilated sella. Pentavalent technetium-99m dimercaptosuccinic acid [99m Tc(V)-DMSA] scintigram (B) revealing marked diffuse accumulation of ${ }^{99 \mathrm{~m}} \mathrm{Tc}(\mathrm{V})$ DMSA within the lesion (tumor-to-background ratio 80.5 ). 

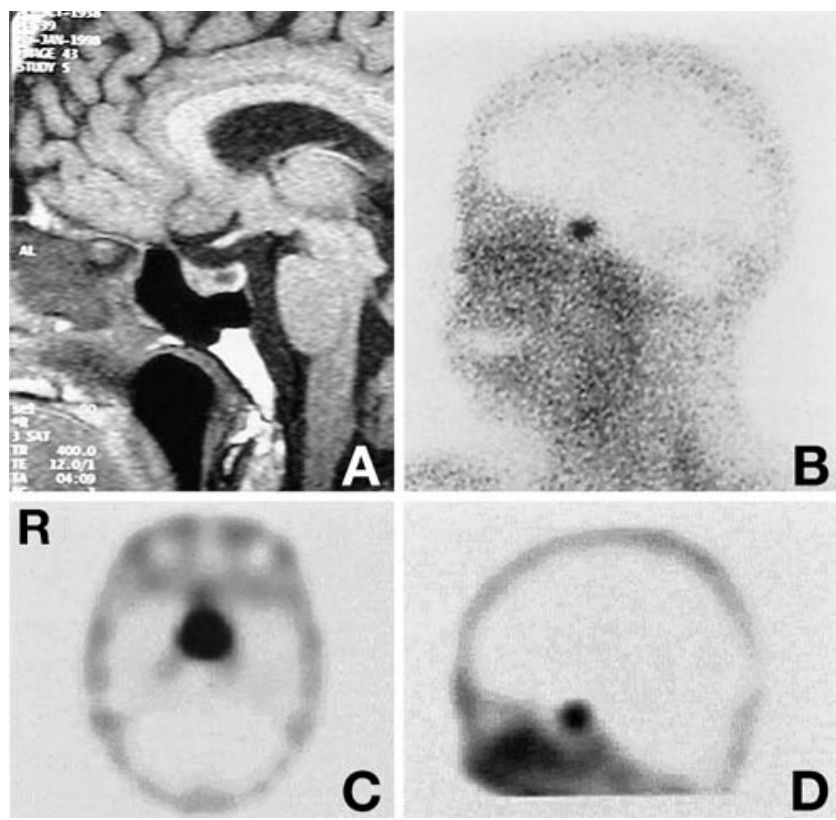

Fig. 3 Case 17. A 60-year-old female with growth hormone-secreting microadenoma. Sagittal $T_{1}$-weighted magnetic resonance image with gadolinium (A) revealing a slightly enhanced mass in the posterior part of the sella. Pentavalent technetium-99m dimercaptosuccinic acid [ ${ }^{99 m}$ Tc(V)-DMSA] scintigram (B) revealing marked accumulation of ${ }^{99 m}$ Tc(V)-DMSA within the lesion. Axial (C) and sagittal (D) ${ }^{99 \mathrm{~m} T c(V)-D M S A}$ single photon emission computed tomography scans revealing ${ }^{99 \mathrm{~m}} \mathbf{T c}(\mathrm{V})$-DMSA accumulation more clearly, even exaggeratedly (tumor-tobackground ratio 47.0 ).

$(19.7 \pm 11.4)$, but there were no statistical differences. Also, there were no significant correlations between T/B ratio and serum hormone levels (PRL $\mathrm{r}=0.475, \mathrm{GH} \mathrm{r}=0.471$ ), or $\mathrm{T} / \mathrm{B}$ ratio and the size of the lesions $(r=0.321)$.

\section{Discussion}

${ }^{99 m} \mathrm{Tc}(\mathrm{V})$-DMSA has the same ligand but different characteristics from the well-known renal imaging agent trivalent ${ }^{99 \mathrm{~m}}$ Tc-DMSA [ $\left.{ }^{99 \mathrm{~m}} \mathrm{Tc}(\mathrm{III})-D M S A\right] .{ }^{4)}$ Scintigraphy with ${ }^{99 \mathrm{~m}} \mathrm{Tc}(\mathrm{V})$-DMSA shows accumulations in medullary thyroid cancer, ${ }^{10)}$ head and neck squamous tumors, ${ }^{15}$ ) skeletal lesions from breast cancer, ${ }^{5)}$ and primary amyloidosis, ${ }^{6)}$ which all have high growth rates. SPECT imaging with ${ }^{99 \mathrm{~m}} \mathrm{Tc}(\mathrm{V})$-DMSA could demonstrate primary brain tumors such as low- or high- grade gliomas, meningiomas, and schwannomas, but not clearly only on the planar

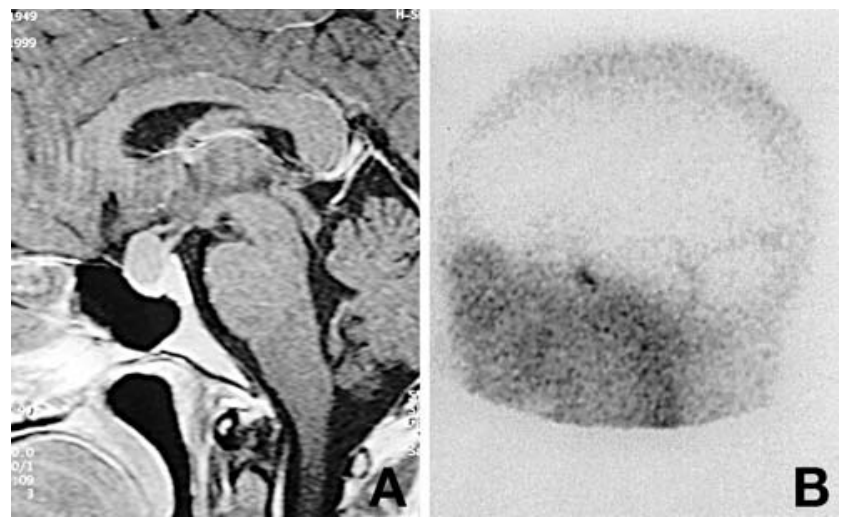

Fig. 4 Case 30. A 56-year-old female with Rathke's cleft cyst. Sagittal $T_{1}$-weighted magnetic resonance image with gadolinium (A) revealing a round mass. Pentavalent technetium-99m dimercaptosuccinic acid [ ${ }^{99 m}$ Tc(V)-DMSA] scintigram (B) revealing partial accumulation of ${ }^{99 \mathrm{~m}} \mathrm{Tc}(\mathrm{V})-\mathrm{DMSA}$, which was supposed to be within the intercavernous sinus.

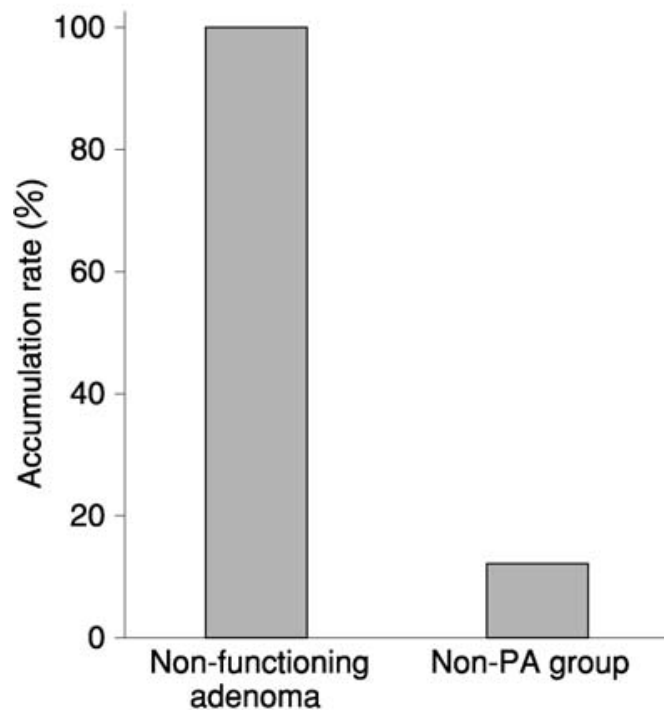

Fig. 5 Pentavalent technetium-99m dimercaptosuccinic acid accumulation rate on planar images showing significant difference $(p<$ 0.01) between non-functioning adenomas $(n=7)$ and the non-pituitary adenoma (PA) group $(\mathbf{n}=16)$.

image. ${ }^{3)}$ 99m Tc(V)-DMSA scintigraphy had an overall sensitivity of $81 \%$ ( 43 of 53) for detecting pituitary adenomas, in particular 15 of 15 non-functioning, 17 of $21 \mathrm{GH}$-secreting, three of six ACTH-secreting, and one mixed adenoma, with a sensitivity of $95 \%$ 
for lesions greater than $10 \mathrm{~mm}$ in size. ${ }^{9)}$

In our series, marked diffuse accumulations of ${ }^{99 \mathrm{~m}} \mathrm{Tc}(\mathrm{V})$-DMSA were observed in 17 of 21 patients with pituitary adenomas, especially seven of seven non-functioning adenomas, but not in patients with non-pituitary adenomas. These results suggest that ${ }^{99 \mathrm{~m}} \mathrm{Tc}(\mathrm{V})$-DMSA can visualize pituitary adenomas clearly, and diffuse accumulation of ${ }^{99 \mathrm{~m}} \mathrm{Tc}(\mathrm{V})-\mathrm{DMSA}$ could differentiate non-functioning adenoma from non-pituitary adenomas using only the planar image.

No detectable accumulation of ${ }^{99 \mathrm{~m}} \mathrm{Tc}(\mathrm{V})-\mathrm{DMSA}$ was observed in our two ACTH-secreting adenomas which were $8 \mathrm{~mm}$ or smaller. No accumulation was found in 10 cases, including three with GH-secreting and three with ACTH-secreting adenomas smaller than $10 \mathrm{~mm}$, suggesting that tumor size may influence the tumor imaging, ${ }^{9)}$ but our series found no correlation between ${ }^{99 \mathrm{~m}} \mathrm{Tc}(\mathrm{V})$-DMSA accumulation and tumor size, and no correlation between $\mathrm{T} / \mathrm{B}$ ratio and tumor size. Accumulation of radiotracers is generally related to the affinity for the tissue or lesions, not the size of the lesion. Marked accumulation was observed in a small lesion by MR imaging in our Case 17 (Fig. 3).

${ }^{99 \mathrm{~m} T c(V)-D M S A}$ accumulation in pituitary adenomas was homogeneous within the solid lesion, but reduced in cystic areas, suggesting that ${ }^{99 \mathrm{~m}} \mathrm{Tc}(\mathrm{V})$ DMSA is accumulated only in the viable part of adenomas. Areas of ${ }^{99 \mathrm{~m}} \mathrm{Tc}(\mathrm{V})-\mathrm{DMSA}$ and ${ }^{99 \mathrm{~m}} \mathrm{Tc}$-methylene diphosphonate accumulation show significant matching in patients with bony metastasis, suggesting that the mechanisms of accumulation are similar. ${ }^{5,13)}{ }^{99 \mathrm{~m}} \mathrm{Tc}(\mathrm{V})$-DMSA accumulated in tumor-like deposits of AL-type amyloid in a patient with primary amyloidosis. ${ }^{6)}$ There is histological evidence that pituitary adenoma may contain amyloid. ${ }^{7,11,12)}$ Although the exact mechanism of tumor accumulation of ${ }^{99 \mathrm{~m}} \mathrm{Tc}(\mathrm{V})-\mathrm{DMSA}$ remains to be elucidated, in general, non-specific trapping is justified. ${ }^{3,9)} \mathrm{We}$ believe that some factors affect ${ }^{99 \mathrm{~m}} \mathrm{Tc}(\mathrm{V})$-DMSA accumulation in pituitary adenomas, such as endocrinic activity, vascularity, and permeability, but not cell proliferation or tumor size.

${ }^{99 \mathrm{~m}} \mathrm{Tc}(\mathrm{V})$-DMSA does not penetrate the intact blood-brain barrier or accumulate in the normal brain tissue or choroid plexus of the cerebral ventricle, ${ }^{9)}$ but ${ }^{99 \mathrm{~m}} \mathrm{Tc}(\mathrm{V})$-DMSA accumulation in normal pituitary gland is controversial. ${ }^{99 \mathrm{~m}} \mathrm{Tc}(\mathrm{V})-\mathrm{DMSA}$ accumulation was observed in the scalp, orbital tissue, and pituitary gland. ${ }^{3)}$ Tracer uptake within the normal pituitary gland may be considered a "pituitary sign" in about $25 \%$ of cases. ${ }^{14)}$ However, ${ }^{99 m} \mathrm{Tc}(\mathrm{V})-$ DMSA may accumulate only in endocrinological "unbalanced" pituitary glands.9) In our series, no
${ }^{99 m} \mathrm{Tc}(\mathrm{V})$-DMSA accumulation was observed in the four normal pituitary glands on planar images. However, ${ }^{99 \mathrm{~m} T c(V)-D M S A}$ accumulated partially near the lesion in two cases of non-pituitary adenomas with clinically normal endocrinological findings. MR imaging indicated that the partial ${ }^{99 \mathrm{~m}} \mathrm{Tc}(\mathrm{V})-$ DMSA accumulation in anterior part of the sella was not in the lesion, but in the intercavernous sinus or pituitary gland. Although there are many variations of the intercavernous sinus, venous flow was slow enough to show positive accumulation on scintigraphy. Therefore, ${ }^{99 \mathrm{~m}} \mathrm{Tc}(\mathrm{V})$-DMSA accumulation may be observed in the intercavernous sinus or pituitary gland in some cases, such as "unbalanced" pituitary gland. Comparison with MR imaging will show whether the accumulation of ${ }^{99 \mathrm{~m}} \mathrm{Tc}(\mathrm{V})-\mathrm{DMSA}$ is located within the lesion or not.

The neuroimaging characteristics of lesions are based primarily on the density differences and extravasation of contrast material in CT and differences in water content and water binding in $M R$ imaging. ${ }^{1)}$ These features that control the signal intensity are frequently similar in various types of tumors, so the differential diagnosis is more often based on anatomical relationships, such as the deformation of adjacent structures. ${ }^{1)}$ In such cases, ${ }^{99 m} \mathrm{Tc}(\mathrm{V})$-DMSA scintigraphy is a very simple and helpful method to distinguish pituitary adenomas from other lesions. ${ }^{99 \mathrm{~m}} \mathrm{Tc}(\mathrm{V})-\mathrm{DMSA}$ scintigraphy could visualize remnant pituitary adenomas after surgery or ectopic pituitary adenomas except for ACTH-secreting adenomas.

\section{References}

1) Bergstrom M, Muhr C, Jossan S, Lilja A, Nyberg G, Langstrom B: Differentiation of pituitary adenoma and meningioma: visualization with positron emission tomography and [11C]-L-deprenyl. Neurosurgery 30: 855-861, 1992

2) Clark WC, Acker JD, Robertson JH, Eggers F, Muhlbauer MS: Reformatted sagittal images in the differential diagnosis of meningiomas and pituitary adenomas with suprasellar extension. Neurosurgery 18: 555-558, 1986

3) Hirano T, Otake H, Shibasaki T, Tamura M, Endo K: Differentiating histologic malignancy of primary brain tumors: pentavalent technetium-99m-DMSA. J Nucl Med 38: 20-26, 1997

4) Hirano T, Tomiyoshi K, Ying JZ, Ishida T, Inoue T, Endo K: Preparation and clinical evaluation of technetium-99m dimercaptosuccinic acid for tumor scintigraphy. Eur J Nucl Med 21: 82-85, 1994

5) Kashyap R, Babbar A, Sahai I, Prakash R, Soni NL, Chauhan UPS: Tc-99m(V)DMSA imaging: a new approach studying metastases from breast carcinoma. Clin Nucl Med 17: 119-122, 1992 
6) Kobayashi H, Sakahara H, Itoh T, Kudoh T, Takagi T, Shibuya K, Nomura S, Hosono M, Endo K, Konishi J: Technetium-99m(V)dimercaptosuccinic acid uptake in intra-abdominal massive deposit of amyloid protein. J Nucl Med 34: 815-817, 1993

7) Kuratsu J, Matsukado Y, Miura M: Prolactinoma of pituitary with associated amyloid-like substances. J Neurosurg 59: 1067-1070, 1983

8) Lamberts SWJ, Krenning EP, Reubi JC: The role of somatostatin and its analogs in the diagnosis and treatment of tumors. Endocr Rev 12: 450-481, 1991

9) Lastoria S, Colao A, Vergara E, Ferone D, Varrella P, Merola B, Lombardi G, Salvatore M: Technetium99m pentavalent dimercaptosuccinic acid imaging in patients with pituitary adenomas. Eur J Endocrinol 133: 38-47, 1995

10) Ohta H, Yamamoto K, Endo K, Mori T, Hamanaka D, Shimazu A, Ikekubo K, Makimoto K, Iida Y, Konishi J, Morita R, Hata N, Horiuchi K, Yokoyama A, Torizuka K, Kuma K: A new imaging agent for medullary carcinoma of the thyroid. J Nucl Med 25: 323-325, 1984

11) Orita T, Yokota T, Uchino F, Harada K, Aoki H, Okamura T: [Amyloid deposits in pituitary adenoma. Immunohistochemical study]. Neurol Med Chir (Tokyo) 26: 951-955, 1986 (Jpn, with Eng abstract)
12) Sakai K, Tsutsui T, Sonobe H, Ohtsuki Y, Sawada A: MRI of pituitary adenoma with extensive amyloid formation. Neuroradiology 41: 358-359, 1999

13) Stone CK, Sisson JC: What causes uptake of technetium-99m methylene diphosphonate by tumors? A case where the tumor appeared to secrete a hypercalcemia-causing substance. J Nucl Med 26: 250-253, 1985

14) Watkinson JC, Lazarus CR, Maisey MN, Clarke SEM: 99mTc(V)DMSA: the pituitary sign. Nucl Med Commun 11: 313-317, 1990

15) Watkinson JC, Lazarus CR, Mistry R, Shaheen $\mathrm{OH}$, Maisey MN, Clarke SE: Technetium-99m(V) dimercaptosuccinic acid in patient with head and neck squamous carcinoma: experience in imaging. J Nucl Med 30: 174-180, 1989

Address reprint requests to: K. Yamamura, M.D., Department of Neurosurgery, Yokohama Minamikyosai Hospital, 1-21-1 Mutsuurahigashi, Kanazawa-ku, Yokohama, Kanagawa 236-0032, Japan.

e-mail: yamamura@urahp.yokohama-cu.ac.jp.

Commentary on this paper appears on the next page. 


\section{Commentary}

This article is a very important contribution for the differential study between non-functioning adenoma from non-pituitary adenomas using only the planar SPECT image with ${ }^{99 m} \mathrm{Tc}(V)-D M S A$. The accumulation of this radiotracer is generally related to the affinity for the tissue or lesions, not the size of the lesion. The authors believe that this accumulation in pituitary adenomas is due to vascularity, permeability and endocrine activity, but not cell proliferation and size of tumour. Sensitivity was $100 \%$ for non-functioning adenomas and $81 \%$ for other cases. It is interesting to note that there was no accumulation of tracer in small ACTH-secreting tumours (2 cases only), and only partial accumulation in craniopharyngioma and Rathke's cyst. When perfected, this would indeed constitute a quite simple method to distinguish pituitary tumours from other lesions and also for the screening of remnant and ectopic pituitary adenomas. The authors are to be congratulated for opening this new diagnostic window for this difficult pathology.

Raul MARINO, Jr., M.D.

Department of Neurosurgery

University of São Paulo Medical School Instituto Neurológico de São Paulo

São Paulo, Brazil

To date, it has been reported that radiopharmaceuticals such as thallium-201 ( $\left.{ }^{201} \mathrm{Tl}\right)$, technetium-99mhexakis-2-methoxyisobutyl isonitrile ${ }^{99 \mathrm{~m}} \mathrm{Tc}$-MIBI) and fluorine-18-fluorodeoxyglucose $\left(\left[{ }^{18} \mathrm{~F}\right] \mathrm{FDG}\right)$ have an affinity for pituitary adenomas. The authors used ${ }_{99 \mathrm{~m}} \mathrm{Tc}(\mathrm{V})$-DMSA to differentiate between pituitary adenomas and other tumors. They reported that ${ }^{99 \mathrm{~m}} \mathrm{Tc}(\mathrm{V})-D M S A$ has a high degree of affinity for pituitary adenomas and is especially useful in differentiating non-functioning adenomas from other tumors. It was suggested that ${ }^{99 \mathrm{~m}} \mathrm{Tc}(\mathrm{V})$-DMSA scintigraphy could possibly be an adjunctive diagnostic procedure for pituitary adenomas. Clinically, the localization diagnosis of ACTH-secreting adenomas is especially problematic. Small ACTH-secreting adenomas are common and the difficulty in making a localization diagnosis is often troubling. When even MR imaging cannot local- ize them, cavernous sinus sampling is required; however, preoperative localization through diagnostic imaging would be extremely useful for neurosurgeons. In their cases, 2 ACTH-secreting adenomas (Cases 20,21) did not show any accumulation. All the PRL-secreting adenomas of the same size (Cases 9, 14-17) showed accumulation; the differences in the accumulation mechanism, whether in the uptake into each adenoma cell or in the retention, are of particular interest. Tumor scintigraphy can image the affinity between tumors and tracers, and can detect even small lesions with high enough affinity. I suggest further studies of ACTH-secreting adenomas to determine whether or not SPECT imaging can be applied to clinical use in future.

Akira Teramoto, M.D. Department of Neurosurgery Nippon Medical School Tokyo, Japan

Pituitary adenoma is the most common tumor in the sella turcica. Consideration of the clinical features, endocrinological investigation and imaging study can indicate what type of tumors is present in this region preoperatively. Using this knowledge, the neurosurgeon can select the optimum surgical treatment, but sometimes the differential diagnosis is difficult, particular in non-functioning pituitary adenomas.

Dr. Yamamura and his colleagues used ${ }^{99 \mathrm{~m}} \mathrm{Tc}(\mathrm{V})-$ DMSA scintigraphy to study 37 patients with sellar and parasellar lesions. ${ }^{99 \mathrm{~m}} \mathrm{Tc}(\mathrm{V})-D M S A$ scintigraphy showed an overall sensitivity of $81 \%$ (17/21 cases) for detecting pituitary adenomas, in particular $100 \%$ for non-functioning adenomas. Four normal pituitary glands were negative. Twelve cases except two of other lesions were negative. This study shows that we can use ${ }^{99 \mathrm{~m}} \mathrm{Tc}(\mathrm{V})$-DMSA scintigraphy for preoperative differentiation between pituitary adenomas and other lesions in sellar and parasellar regions. This is significant for neurosurgeons to select the optimal treatment.

Shu-yuan YANG, M.D. Department of Neurosurgery Tianjin Medical University General Hospital Tianjin, P.R.C. 